\title{
On The Temperature Field of a Viscous Reacting Flow Near a Moving Wall with Thermal Radiation
}

\author{
B.I. Olajuwon and R.O. Ayeni \\ Department of Pure and Applied Mathematics \\ Ladoke Akintola University of Technology, Ogbomoso, Nigeria
}

\begin{abstract}
We examine the temperature field of a viscous reacting flow near a moving wall with thermal radiation. Of particular interest is the effect of thermal radiation parameter and the Frankkamenetskii parameter on the flow.
\end{abstract}

Key words: Frank Kamenetskii Parameters, Thermal Radiation

\section{INTRODUCTION}

Many Scientist have shown great interest in the study of the flow of reacting fluid. [1] revisited the work of Frank-kamenetskii done forty years earlier introducing approximation based on the large activation energy to construct a thermal theory of spontaneous combustion.

[2] examined self-similar solution of a viscous reacting flow. They presented conditions for existence and uniqueness of the solution.

[3] investigated strong detonation in a converging vessel. They showed that when Frank-kamenetskii parameter differ even only by $1 / 30$ there is appreciable difference in the temperature along the converging vessel.

Researchers have also examined many problems involving flow near a moving wall. [4] examined momentum and heat transfer on a continuously moving surface in a power law fluid. Their result includes situations when the velocity is non-linear and when the surface is stretching linearly. [5] discussed the flow and heat transfer in a power law fluid over a non-isothermal stretching sheet. Their results showed that the friction factor and heat transfer depend strongly on the flow parameter.

[6] investigated the problem of a non-Newtonian viscoelastic fluid obeying the Walters' model with heat transfer over a continuous surface in parallel stream using the finite difference method. [7] discussed the problem of the flow and heat in a non-Newtonian fluid with micro rotation past a stretching sheet.

In this study, we examined a viscous reacting flow with thermal radiation. We investigated the effect of the thermal radiation parameter $\left(\mathrm{T}_{\mathrm{R}}\right)$ and the FrankKamenetskii parameter $(\mathrm{M})$ on the flow.

Mathematical Formulation: We consider the steady state flow and the relevant governing equations are as stated below.
Continuity equation

$$
\frac{\partial u}{\partial x}+\frac{\partial u}{\partial y}=0
$$

momentum equation

$$
\rho\left(u \frac{\partial u}{\partial x}+v \frac{\partial u}{\partial y}\right)=\mu \frac{\partial^{2} u}{\partial y^{2}}
$$

Energy equation:

$$
\rho C_{p}\left(u \frac{\partial T}{\partial x}+v \frac{\partial T}{\partial y}\right)=K \frac{\partial^{2} T}{\partial y^{2}}+\frac{\partial q_{r}}{\partial y}+A Q e^{-E / R T}
$$

Where:

$$
q_{r}=-e \sigma \frac{\partial T^{4}}{\partial y}
$$

Together with boundary condition

$$
\mathrm{u}=\mathrm{Ax}, \mathrm{v}=\mathrm{V}_{\mathrm{m}}, \quad \mathrm{T}=\mathrm{T}_{\mathrm{o}} \quad \text { at } \quad \mathrm{y}=0
$$

and

$\mathrm{u}=0, \quad \mathrm{~T}=\mathrm{T}_{\infty} \quad$ as $\quad \mathrm{y}=\infty$.

Note:

$\mathrm{u}$ is the $\mathrm{x}$ component velocity

$\mathrm{v}$ is the $\mathrm{y}$ component velocity

$\rho$ is the density

$\mathrm{T}$ is the temperature

$\mathrm{Q}$ is the boundary layer

$\mathrm{E}$ is the Activator energy

$\mathrm{q}_{\mathrm{r}}$ is the radiant energy 
$\mathrm{e}$ is the emmisivity

$\sigma$ is the Stefan-Boltzmenn constant

\section{Method of Solution:}

Let

$$
\theta=\left(\mathrm{T}-\mathrm{T}_{\mathrm{o}}\right) \frac{\mathrm{E}}{\mathrm{RT}_{\mathrm{o}}^{2}}
$$

Obtaining the Taylor series expansion for $\mathrm{T}^{4}$, neglecting higher order terms,

$\mathrm{T}^{4}=4 T_{\infty}^{3} \mathrm{~T}-3 T_{\infty}^{4}$

Using equation (3.1), (3.2), and (2.4) in equation (2.3)

$\mathrm{u} \frac{\partial \theta}{\partial \mathrm{x}}+\mathrm{v} \frac{\partial \theta}{\partial \mathrm{y}}=\frac{\mathrm{v}}{\mathrm{pr}}\left(1-\mathrm{T}_{\mathrm{R}}\right) \frac{\partial^{2} \theta}{\partial \mathrm{y}^{2}}+\mathrm{Me}^{\theta}$ (3.3)

Where

$\mathrm{T}_{\mathrm{R}}=\frac{4 e \sigma T_{\infty}^{3}}{k}$, Thermal radiation parameter

$\mathrm{M}=\frac{\mathrm{AE} \theta}{\mathrm{RT}_{0}^{2} \rho \mathrm{C}_{\mathrm{p}}}$, Frank-Kamenetskii parameter
Now, define a similarity variable

$\eta=\mathrm{y} \sqrt{\mathrm{A} / \mathrm{v}}$

such that

$u=A x f^{\prime}(\eta), v=-(A v)^{1 / 2} f(\eta)$

Using equation (3.4) and (3.5) in equation (2.2) we have

$f^{\prime \prime \prime}+f f^{\prime \prime}-\left(f^{\prime}\right)^{2}=0$

$f(0)=0, f^{\prime}(0)=1, f^{\prime}(\infty)=0$

Equation (3.6) together with conditions (3.7) had been solved by [8] and obtained

$f(\eta)=1-e^{-\eta}$

Defining

$\theta=\left(\frac{v}{A}\right)^{1 / 2} \mathrm{~g}(\eta)$

Satisfying equation (3.4), equation (3.3) becomes

$\left(\frac{v}{\mathrm{~A}}\right)^{1 / 2}\left(\frac{v}{\mathrm{Pr}}\right)\left(1-\mathrm{T}_{\mathrm{R}}\right) \mathrm{g}^{\prime \prime}+(\mathrm{A} v)^{1 / 2} \mathrm{fg}^{\prime}+\mathbf{M} \exp \left[\left(\frac{v}{\mathrm{~A}}\right) \mathrm{g}(\eta)\right]=0$

$\mathrm{g}(0)=1, \mathrm{~g}^{\prime}(0)=-1, \mathrm{~g}(\infty)=0$

Solving equation (3.10) numerically, taking A $=1 v=1$, using shooting method technique.

Let;

$\left(\begin{array}{l}x_{1} \\ x_{2} \\ x_{3}\end{array}\right)=\left(\begin{array}{l}\eta \\ g \\ g^{\prime}\end{array}\right)$

We consider

$\left(\begin{array}{l}x_{1}^{1} \\ x_{2}^{1} \\ x_{3}^{1}\end{array}\right)=\left(\begin{array}{c}1 \\ x_{3} \\ \frac{\left(e^{-x_{1}}-1\right) \operatorname{Pr} x_{3}}{1-T_{R}}-\frac{M P r e^{x_{2}}}{1-T_{R}}\end{array}\right)$

Together with the initial condition 


$$
\left(\begin{array}{l}
x_{1}(0) \\
x_{2}(0) \\
x_{3}(0)
\end{array}\right)=\left(\begin{array}{l}
0 \\
1 \\
-1
\end{array}\right)
$$

The results are as presented in Figs. 1 and 2 .

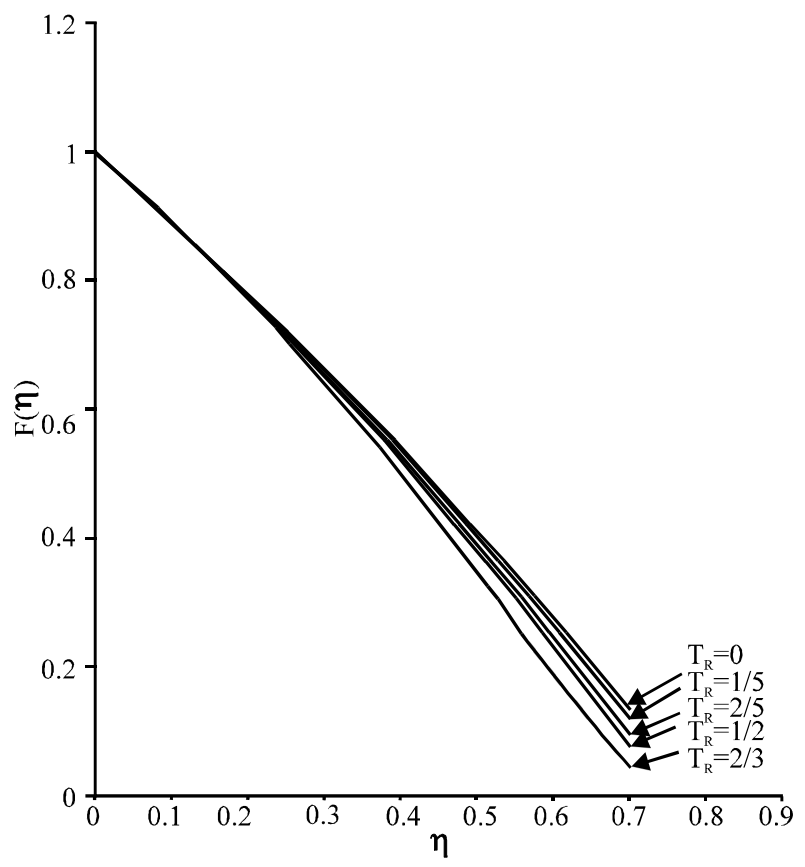

Fig. 1: Effect of Thermal Radiation Parameter

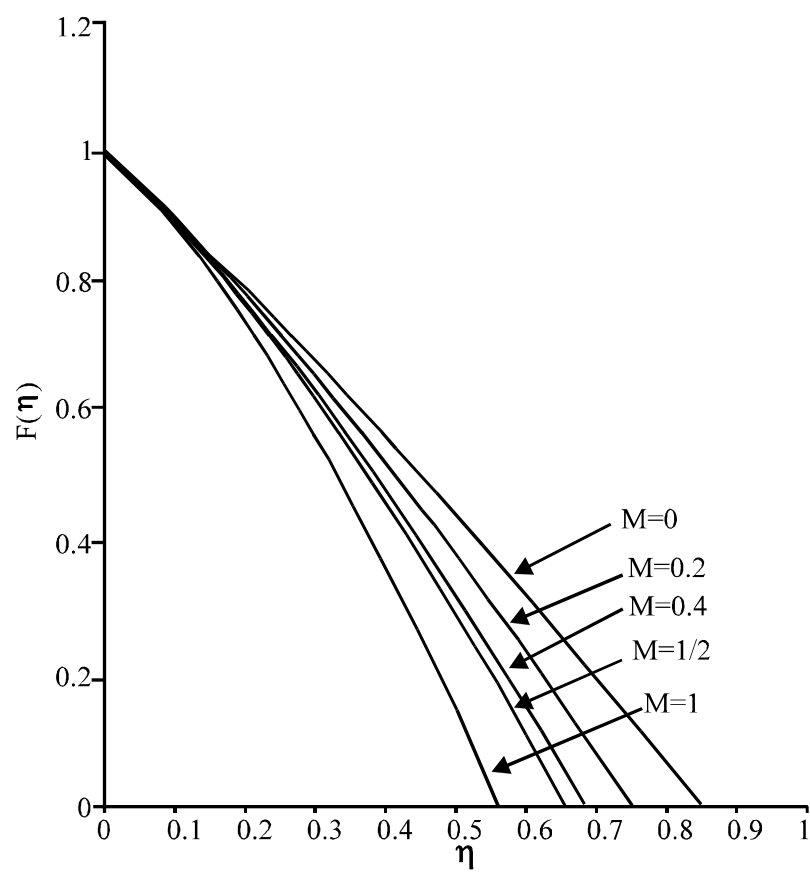

Fig. 2: Effect of Frank-Kamenetskii Parameter

\section{RESULTS AND DISCUSSION}

The Fig. 1 shows the effect of the thermal radiation parameter on the temperature field of viscous reacting flow at a constant value for Frank-Kamenetskii parameter. The temperature difference is studied for the values of thermal radiation parameter $T_{R}=0,1 / 5,2 / 5$, $1 / 2$ and $2 / 3$. As the thermal radiation increases the temperature decrease. This is as result of energy lost by the reaction through radiation. Hence, thermal radiation account for heat loss and this lower the temperature.

The Fig. 2 shows the effect of Frank - Kamenetskii parameter on the temperature field of a viscous reacting flow. The temperature difference is examined for the values of Frank - Kamenetskii parameter $\mathbf{M}=0,1 / 5$, $2 / 5,1 / 2$ and 1 . As the Frank - Kamenetskii parameter increases the temperature increases. Infact, the Frank Kamenetskii parameter has appreciable influence on the temperature difference of the flow.

\section{REFERENCES}

1. Buckmaster, J.O. and G.S.S. Ludford, 1983. Lectures on mathematical combustion. SIAM Conference series in Applied Mathematics, 43, Philadelphia.

2. Alao, F.I. and R.O. Ayeni, 2001. Existence and Uniqueness for self-similar solutions for a viscous reacting flow. J. Nig. Ass. Math. Phys., 5: 177-184.

3. Olanrewaju, P.O. and R.O. Ayeni, 2001. Effect of Frank-Kamentskii parameter on strong detonation in a converging vessel. J. Nig. Ass. Math. Phys., 5: 267-272.

4. Howell, T.G., D.R. Jeng and K.J. De Witt, 1997. Momentum and heat transfer on a continuous moving surface in a power law fluid. Int. J. Heat and mass Transfer, 40: 1853-1861.

5. Hassanien, I.A., A.A. Abdullah and R.S.R. Gorla, 1998. Heat transfer in a power law fluid over a non-isothermal stretching sheet. Math. Comp. Modeling, 28: 105-116.

6. Hassanien, I.A., 1992. Flow and heat transfer from a continuous surface in parallel free stream of visco-elastic second order fluid. Appl. Sci. Res. J., 49: 335-344.

7. Hassanen, I.A. and R.S.R. Gorla, 1990. Heat transfer to a micropolar fluid from a nonisothermal stretching sheet with juction and blowing. Acta Mechanica J., 84: 191-201.

8. Crane, L.J. 1970. Flow past a stretching plane. Z. Angem Math. Phy., 21: 645-647. 